\title{
Quantifying the impact of aerosol scattering on the retrieval of methane from airborne remote sensing measurements
}

\author{
Yunxia Huang ${ }^{1,2}$, Vijay Natraj ${ }^{3}$, Zhao-Cheng Zeng ${ }^{2,4}$, Pushkar Kopparla ${ }^{5}$, and Yuk L. Yung ${ }^{2,3}$ \\ ${ }^{1}$ School of Science, Nantong University, Nantong, 226007, China \\ ${ }^{2}$ Division of Geological and Planetary Sciences, California Institute of Technology, Pasadena, CA 91125, USA \\ ${ }^{3}$ Jet Propulsion Laboratory, California Institute of Technology, Pasadena, CA 91109, USA \\ ${ }^{4}$ Joint Institute for Regional Earth System Science and Engineering, University of California, Los Angeles, CA 90095, USA \\ ${ }^{5}$ Graduate School of Frontier Sciences, The University of Tokyo, Kashiwa, Chiba 277-0882, Japan
}

Correspondence: Vijay Natraj (vijay.natraj@jpl.nasa.gov)

Received: 20 February 2020 - Discussion started: 12 May 2020

Revised: 14 October 2020 - Accepted: 16 October 2020 - Published: 15 December 2020

\begin{abstract}
As a greenhouse gas with strong global warming potential, atmospheric methane $\left(\mathrm{CH}_{4}\right)$ emissions have attracted a great deal of attention. Although remote sensing measurements can provide information about $\mathrm{CH}_{4}$ sources and emissions, accurate retrieval is challenging due to the influence of atmospheric aerosol scattering. In this study, imaging spectroscopic measurements from the Airborne Visible/Infrared Imaging Spectrometer - Next Generation (AVIRIS-NG) in the shortwave infrared are used to compare two retrieval techniques - the traditional matched filter (MF) method and the optimal estimation (OE) method, which is a popular approach for trace gas retrievals. Using a numerically efficient radiative transfer model with an exact singlescattering component and a two-stream multiple-scattering component, we also simulate AVIRIS-NG measurements for different scenarios and quantify the impact of aerosol scattering in the two retrieval schemes by including aerosols in the simulations but not in the retrievals. The presence of aerosols causes an underestimation of $\mathrm{CH}_{4}$ in both the MF and $\mathrm{OE}$ retrievals; the biases increase with increasing surface albedo and aerosol optical depth (AOD). Aerosol types with high single-scattering albedo and low asymmetry parameter (such as water-soluble aerosols) induce large biases in the retrieval. When scattering effects are neglected, the MF method exhibits lower fractional retrieval bias compared to the $\mathrm{OE}$ method at high $\mathrm{CH}_{4}$ concentrations (2-5 times typical background values) and is suitable for detecting strong $\mathrm{CH}_{4}$ emissions. For an AOD value of 0.3, the fractional biases of the MF retrievals are between $1.3 \%$ and $4.5 \%$, while the cor-
\end{abstract}

responding values for OE retrievals are in the $2.8 \%-5.6 \%$ range. On the other hand, the OE method is an optimal technique for diffuse sources $(<1.5$ times typical background values), showing up to 5 times smaller fractional retrieval bias (8.6\%) than the MF method (42.6\%) for the same AOD scenario. However, when aerosol scattering is significant, the OE method is superior since it provides a means to reduce biases by simultaneously retrieving AOD, surface albedo, and $\mathrm{CH}_{4}$. The results indicate that, while the MF method is good for plume detection, the OE method should be employed to quantify $\mathrm{CH}_{4}$ concentrations, especially in the presence of aerosol scattering.

\section{Introduction}

Atmospheric methane $\left(\mathrm{CH}_{4}\right)$ is about 85 times more potent per unit mass at warming the Earth than carbon dioxide $\left(\mathrm{CO}_{2}\right)$ on a 20-year timescale (Myhre et al., 2013), implying that reduction in $\mathrm{CH}_{4}$ emissions could be very efficient to slow down global warming in the near term. Global mean $\mathrm{CH}_{4}$ concentrations have increased from $\sim 700 \mathrm{ppb}$ in the preindustrial era to more than $1860 \mathrm{ppb}$ as of 2019 (NOAA, 2019). The most effective sink of atmospheric $\mathrm{CH}_{4}$ is the hydroxyl radical $(\mathrm{OH})$ in the troposphere. $\mathrm{CH}_{4}$ reacts with $\mathrm{OH}$ to reduce the oxidizing capacity of the atmosphere and generate tropospheric ozone. Increasing emissions of $\mathrm{CH}_{4}$ reduce the concentration of $\mathrm{OH}$ in the atmosphere. With less $\mathrm{OH}$ to react with, the lifespan of $\mathrm{CH}_{4}$ could also increase, resulting 
in greater $\mathrm{CH}_{4}$ concentrations (Holmes et al., 2013). Soils also act as a major sink for atmospheric methane through the methanotrophic bacteria that reside within them.

Significant natural $\mathrm{CH}_{4}$ sources include wetlands $(\mathrm{Bu}-$ bier and Moore, 1994; Macdonald et al., 1998; Gedney et al., 2004), geological seeps (Kvenvolden and Rogers, 2005; Etiope et al., 2009), ruminant animals, and termites. In addition, increased surface and ocean temperatures associated with global warming may increase $\mathrm{CH}_{4}$ emissions from melting permafrost (Woodwell et al., 1998; Walter et al., 2006; Schaefer et al., 2014; Schuur et al., 2015) and methane hydrate destabilization (Kvenvolden, 1988; Archer, 2007). Human activity also contributes significantly to the total $\mathrm{CH}_{4}$ emissions. Rice agriculture is one of the most important anthropogenic sources of $\mathrm{CH}_{4}$ (Herrero et al., 2016; Schaefer et al., 2016). Other sources include landfills (Themelis and Ulloa, 2007), wastewater treatment, biomass burning, and methane slip from gas engines. Global fugitive $\mathrm{CH}_{4}$ emissions from coal mining (Kort et al., 2014), natural gas and oil systems (Alvarez et al., 2018), hydraulic fracturing ("fracking") of shale gas wells (Howarth et al., 2011; Howarth, 2015, 2019), and residential and commercial natural gas distribution sectors (He et al., 2019) are also of increasing concern. Although the sources and sinks of methane are reasonably well known, there are large uncertainties in their relative amounts and in the partitioning between natural and anthropogenic contributions (Nisbet et al., 2014, 2016). This uncertainty is exemplified by the $\mathrm{CH}_{4}$ "hiatus", which refers to the observed stabilization of atmospheric $\mathrm{CH}_{4}$ concentrations from 1999-2006, and the renewed rise thereafter (Kirschke et al., 2013).

Satellite monitoring of $\mathrm{CH}_{4}$ can be broadly divided into three categories: solar backscatter, thermal emission, and lidar (Jacob et al., 2016). The first solar backscattering mission was SCIAMACHY (Frankenberg et al., 2006), which was operational from 2003-2012 and observed the entire planet once every $7 \mathrm{~d}$. It was followed by GOSAT in 2009 (Kuze et al., 2016) and subsequently the next-generation GOSAT- 2 in 2018 (Glumb et al., 2014). In between, the TROPOMI mission was also launched in 2017, which observes the planet once daily with a high spatial resolution of $7 \times 7 \mathrm{~km}^{2}$ (Butz et al., 2012; Veefkind et al., 2012). CarbonSat (Buchwitz et al., 2013) is another proposed mission to measure $\mathrm{CH}_{4}$ globally from solar backscatter with a very fine spatial resolution $\left(2 \times 2 \mathrm{~km}^{2}\right)$ and high precision $(0.4 \%)$. GHGSat-D (McKeever et al., 2017; Varon et al., 2019; Jervis et al., 2020) measures between $1630-1675 \mathrm{~nm}$, with an effective pixel resolution of $50 \times 50 \mathrm{~m}^{2}$ over targeted $12 \times 12 \mathrm{~km}^{2}$ scenes, and is intended to detect $\mathrm{CH}_{4}$ emissions from individual industrial sites. In contrast, MethaneSAT (Wofsy and Hamburg, 2019) has a pixel size of $1-2 \mathrm{~km}^{2}$ and a wide field of view $\left(200 \mathrm{~km}^{2}\right)$ and can quantify diffuse $\mathrm{CH}_{4}$ emission sources over large areas. Thermal infrared observations of $\mathrm{CH}_{4}$ are available from the IMG (Clerbaux et al., 2003), AIRS (Xiong et al., 2008), TES (Worden et al., 2012), IASI
(Xiong et al., 2013), and CrIS (Gambacorta et al., 2016) instruments. These instruments provide day and night measurements at spatial resolutions ranging from $5 \times 8 \mathrm{~km}^{2}$ (TES) to $45 \times 45 \mathrm{~km}^{2}$ (AIRS). GEO-CAPE (Fishman et al., 2012), GeoFTS (Xi et al., 2015), G3E (Butz et al., 2015), and GeoCarb (Polonsky et al., 2014) are proposed geostationary instruments (GeoCarb was selected by NASA under the Earth Venture - Mission program), which when operational will have resolutions of $2-5 \mathrm{~km}$ over regional scales. The MERLIN lidar instrument (Kiemle et al., 2014) scheduled for launch in 2021 will measure $\mathrm{CH}_{4}$ by employing a differential absorption lidar.

By combining a large number of footprints and high spatial resolution, airborne imaging spectrometers are also well suited for mapping local $\mathrm{CH}_{4}$ plumes. The Airborne Visible/Infrared Imaging Spectrometer - Next Generation (AVIRIS-NG) measures reflected solar radiance across more than 400 channels between 380 and $2500 \mathrm{~nm}$ (Green et al., 1998; Thompson et al., 2015). Strong $\mathrm{CH}_{4}$ absorption features present between 2100 and $2500 \mathrm{~nm}$ can be observed at a spectral resolution of $5 \mathrm{~nm}$ full width at half maximum (FWHM). A number of approaches have been developed to retrieve $\mathrm{CH}_{4}$ from such hyperspectral data. Roberts et al. (2010) used a spectral residual approach between 2000 and $2500 \mathrm{~nm}$ and Bradley et al. (2011) employed a band ratio technique using the $2298 \mathrm{~nm} \mathrm{CH}_{4}$ absorption band and $2058 \mathrm{~nm} \mathrm{CO} \mathrm{CO}_{2}$ absorption band. However, these techniques are not suited for terrestrial locations that have lower albedos and have spectral structure in the shortwave infrared (SWIR). A cluster-tuned matched filter technique was demonstrated to be capable of mapping $\mathrm{CH}_{4}$ plumes from marine and terrestrial sources (Thorpe et al., 2013) as well as $\mathrm{CO}_{2}$ from power plants (Dennison et al., 2013); however, this method does not directly quantify gas concentrations. Frankenberg et al. (2005) developed an iterative maximum a posteriori differential optical absorption spectroscopy (IMAP-DOAS) algorithm that allows for uncertainty estimation. Thorpe et al. (2014) adapted the IMAP-DOAS algorithm for gas detection in AVIRIS imagery. In addition, they developed a hybrid approach using singular value decomposition and IMAPDOAS as a complementary method of quantifying gas concentrations within complex AVIRIS scenes.

Accurate assessment of $\mathrm{CH}_{4}$ emissions is particularly challenging in the presence of aerosols because the latter introduce uncertainties in the light path if not accounted for. In fact, $\mathrm{CH}_{4}$ emissions are frequently correlated with pollution due to concurrent aerosol emissions. For large aerosols (such as dust), the low Ångström exponent values result in high aerosol optical depth (AOD) values even in the wavelength range from 2000 to $2500 \mathrm{~nm}$ (Seinfeld and Pandis, 2006; Zhang et al., 2015). Therefore, it is important to obtain a clear understanding of aerosol impacts on $\mathrm{CH}_{4}$ retrievals. In this study, SWIR AVIRIS-NG measurements are used to analyze the impact of aerosol scattering on $\mathrm{CH}_{4}$ retrievals. Further, using an accurate but numerically efficient radiative transfer 
(RT) model (Spurr and Natraj, 2011), we simulate AVIRISNG measurements with varying aerosol amounts and quantify the impact of aerosol scattering using two retrieval techniques, the traditional matched filter (MF) method and the optimal estimation (OE) method that is widely used in trace gas remote sensing. This article is organized as follows. The $\mathrm{MF}$ and $\mathrm{OE}$ retrieval methods are described in Sect. 2. Section 3 focuses on analysis of a sample $\mathrm{CH}_{4}$ plume detected by AVIRIS-NG measurements and compares retrievals using the MF and OE methods. Section 4 presents a detailed evaluation of aerosol impacts on the two retrieval methods through simulations of AVIRIS-NG spectra for different geophysical parameters. Section 5 provides a summary of the work and discusses future research.

\section{Methods}

\subsection{MF method}

Real-time remote detection using AVIRIS-NG measurements is traditionally based on the MF method (Frankenberg et al., 2016). In this method, the background spectra are assumed to be distributed as a multivariate Gaussian $\mathcal{N}$ with covariance matrix $\boldsymbol{\Sigma}$ and background mean radiance $\boldsymbol{\mu}$. If $H_{0}$ is a scenario without $\mathrm{CH}_{4}$ enhancement and $H_{1}$ is one with $\mathrm{CH}_{4}$ enhancement, the MF approach is equivalent to a hypothesis test between the two scenarios:

$H_{0}: \boldsymbol{L}_{m} \sim \mathcal{N}(\boldsymbol{\mu}, \boldsymbol{\Sigma})$,

$H_{1}: \boldsymbol{L}_{m} \sim \mathcal{N}(\boldsymbol{\mu}+\boldsymbol{t} \alpha, \boldsymbol{\Sigma})$,

where $\boldsymbol{L}_{m}$ is the measurement radiance; $\boldsymbol{t}$ is the target signature, which is defined in Eq. (4); and $\alpha$ is the enhancement value, denoting a scaling factor for the target signature that perturbs the background $\boldsymbol{\mu}$. If $\boldsymbol{x}$ is a vector of measurement spectra with one element per wavelength, $\alpha(\boldsymbol{x})$ can be written, based on maximum likelihood estimates (Manolakis et al., 2014), as follows:

$\alpha(\boldsymbol{x})=\frac{(\boldsymbol{x}-\boldsymbol{\mu})^{T} \boldsymbol{\Sigma}^{-1} \boldsymbol{t}}{\boldsymbol{t}^{T} \boldsymbol{\Sigma}^{-1} \boldsymbol{t}}$.

We utilize the same definitions as in Frankenberg et al. (2016). Specifically, the enhancement value $\alpha(\boldsymbol{x})$ denotes the thickness and concentration within a volume of equivalent absorption and has units of parts per million $\times$ meter $(\mathrm{ppm} \times \mathrm{m})$. The target signature $\boldsymbol{t}$ refers to the derivative of the change in measured radiance with respect to a change in absorption path length due to an optically thin absorbing layer of $\mathrm{CH}_{4}$. Note that this definition has the disadvantage that the accuracy of the result degrades when the absorption is strong and further attenuation becomes nonlinear. At a particular wavelength $\lambda, t$ can be expressed as

$t(\lambda)=-\kappa(\lambda) \mu(\lambda)$

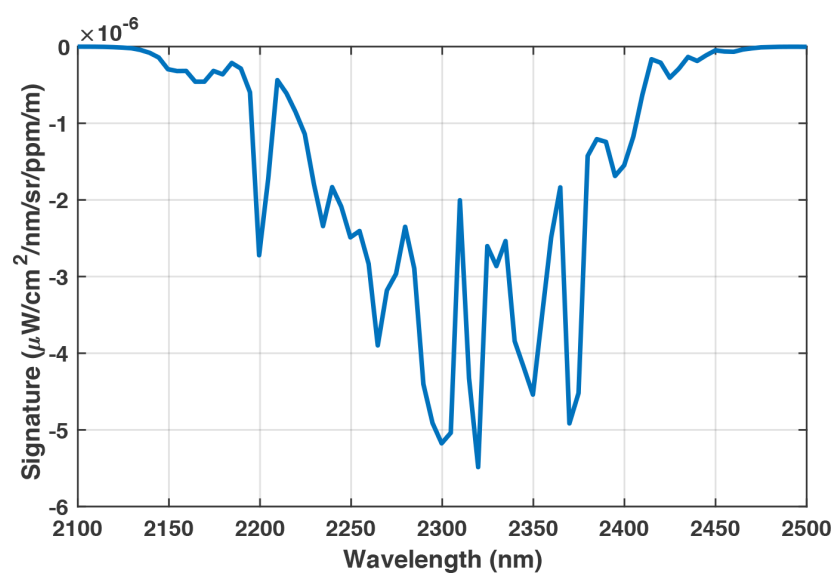

Figure 1. The target signature used for the matched filter method.

where $\kappa$ is the absorption coefficient for a near-surface plume with units of $\mathrm{ppm}^{-1} \mathrm{~m}^{-1}$. This is different from the units of $\mathrm{m}^{2} \mathrm{~mol}^{-1}$ traditionally used for the absorption coefficient $\kappa_{\text {trad }}$ in trace gas remote sensing. Using the ideal gas law to express the volume $V$ (in liters) occupied by $1 \mathrm{~mol}$ of $\mathrm{CH}_{4}$ at the temperature and pressure corresponding to the plume altitude ( $V=22.4$ at standard temperature and pressure), and the relations $1 \mathrm{~L}=10^{-3} \mathrm{~m}^{3}$ and $1 \mathrm{ppm}=10^{-6}$, we obtain the following expression for unit conversion (units in parentheses):

$$
\begin{aligned}
\kappa_{\text {trad }}\left[\mathrm{m}^{2} \mathrm{~mol}^{-1}\right]= & \kappa\left[\mathrm{ppm}^{-1} \mathrm{~m}^{-1}\right] \times V\left[\mathrm{~L} \mathrm{~mol}^{-1}\right] \\
& \times 10^{-3}\left[\mathrm{~m}^{3} \mathrm{~L}^{-1}\right] / 10^{-6}\left[\mathrm{ppm}^{-1}\right] .
\end{aligned}
$$

Figure 1 shows the target signature, which is calculated based on HITRAN absorption cross sections (Rothman et al., 2009). The background mean radiance $\mu$ used in Eq. (4) is based on the AVIRIS-NG measurement shown in Fig. 2; this is described in more detail in Sect. 3.

\subsection{OE method}

The OE method is widely used for the remote sensing retrieval of satellite measurements, such as from the Orbiting Carbon Observatory-2 (OCO-2; O'Dell et al., 2018), the Spinning Enhanced Visible and InfraRed Imager (SEVIRI; Merchant et al., 2013), and the Greenhouse Gases Observing Satellite (GOSAT; Yoshida et al., 2013). It combines an explicit (typically nonlinear) forward model of the atmospheric state, a (typically Gaussian) prior probability distribution for the variabilities and a (typically Gaussian) distribution for the spectral measurement errors. In addition, the Bayesian framework used by the $\mathrm{OE}$ approach allows new information (from measurements) to be combined with existing information (e.g., from models). In many applications, the forward model is nonlinear, and obtaining the optimal solution requires iterative techniques such as the Levenberg-Marquardt method (Rodgers, 2000), which has been routinely applied 

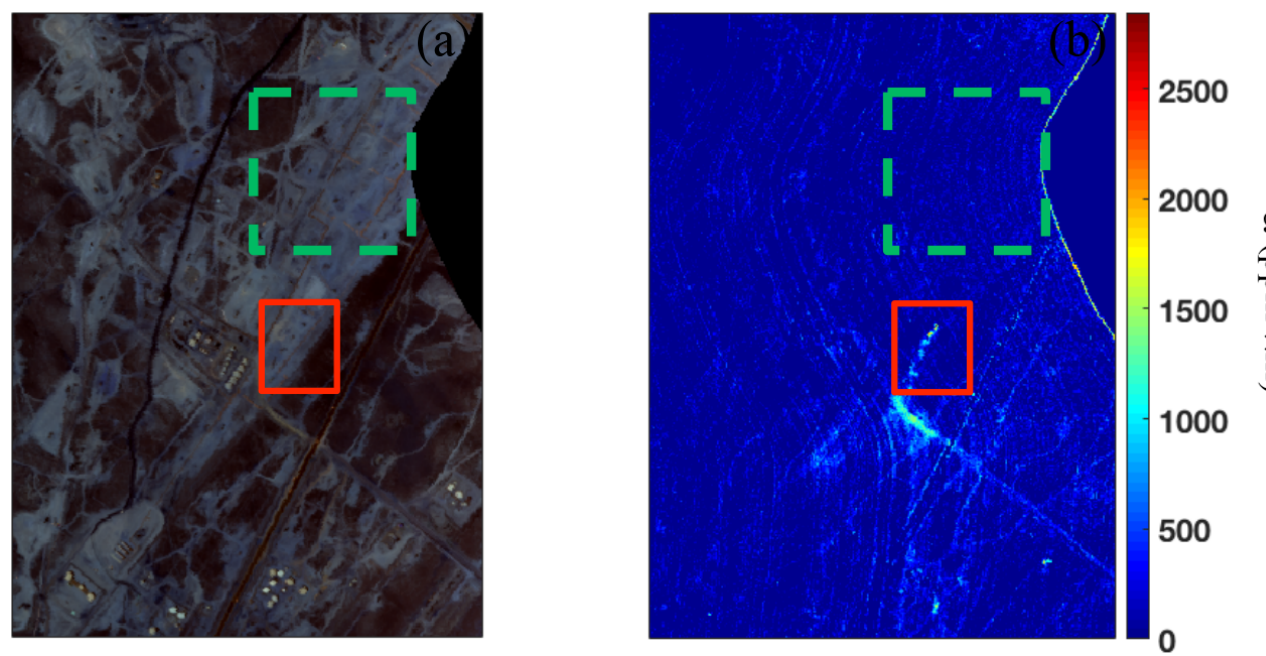

Figure 2. (a) RGB image of flight data from 4 September 2014 (ang20140904t204546). Adapted from Thompson et al. (2015). (b) $\mathrm{CH}_{4}$ enhancement value $\alpha(\mathrm{ppm} \times \mathrm{m})$ obtained by the MF method. An emission source is shown in the solid red box and the background region near the target for the MF calculation is indicated by the dashed green box.

to study the impacts of measurement parameters on the retrieval process (see, e.g., Zhang et al., 2015). The iteration in this algorithm follows the procedure below.

$$
\begin{aligned}
\boldsymbol{x}_{i+1}= & \boldsymbol{x}_{i}+\left[(1+\gamma) \mathbf{S}_{\mathrm{a}}^{-1}+\mathbf{K}_{i}^{T} \mathbf{S}_{\epsilon}^{-1} \mathbf{K}_{i}\right]^{-1} \\
& \left\{\mathbf{K}_{i}^{T} \mathbf{S}_{\epsilon}^{-1}\left[\boldsymbol{y}-F\left(\boldsymbol{x}_{i}\right)\right]-\mathbf{S}_{\mathrm{a}}^{-1}\left[\boldsymbol{x}_{i}-\boldsymbol{x}_{\mathrm{a}}\right]\right\},
\end{aligned}
$$

where $\boldsymbol{x}$ is a state vector of surface and atmospheric properties, $\mathbf{S}_{\mathrm{a}}$ is the a priori covariance matrix, $\mathbf{S}_{\epsilon}$ is the spectral radiance noise covariance matrix, $\mathbf{K}$ is the Jacobian matrix, $\boldsymbol{x}_{\mathrm{a}}$ is the a priori state vector, and $\gamma$ is a parameter determining the size of each iteration step. The measured spectral radiance is denoted as $\boldsymbol{y} ; F(\boldsymbol{x})$ is the simulated radiance obtained from the forward model. For the retrieval of $\mathrm{CH}_{4}$ from AVIRIS-NG measurements, the state vector includes the total column amounts of $\mathrm{CH}_{4}$ and $\mathrm{H}_{2} \mathrm{O}$, while for the retrievals from synthetic spectra, the $\mathrm{H}_{2} \mathrm{O}$ concentration is fixed and the state vector only includes the $\mathrm{CH}_{4}$ total column. The a priori values are within $10 \%$ of the true values; a priori errors are assumed to be $20 \%$ for all state vector elements. The retrieved results are shown as the column-averaged mixing ratio $\left(\mathrm{XCH}_{4}, \mathrm{ppm}\right)$. Aerosols are not included in the state vector for both the real and synthetic retrievals. They are, however, considered in the forward model for the synthetic simulations. Table 1 (WCRP, 1986) lists optical properties for four basic aerosol types (dust, water soluble, oceanic, and soot). Table 2 (WCRP, 1986) shows the corresponding properties for three aerosol models that are defined as mixtures of the basic components from Table 1. We employ the Henyey-Greenstein phase function (Henyey and Greenstein, 1941), where aerosol composition is determined by two parameters: single-scattering albedo (SSA) and asymmetry parameter $(g)$. The surface albedo is also not retrieved; for both
Table 1. Optical properties of basic aerosol types (WCRP, 1986).

\begin{tabular}{lcccc}
\hline & Dust-like & $\begin{array}{c}\text { Water } \\
\text { soluble }\end{array}$ & Oceanic & Soot \\
\hline SSA & 0.805 & 0.799 & 0.970 & 0.014 \\
$g$ & 0.926 & 0.550 & 0.816 & 0.092 \\
\hline
\end{tabular}

real and synthetic retrievals, it is held fixed and assumed to be independent of wavelength.

\section{Detection and retrieval of $\mathrm{CH}_{4}$ from AVIRIS-NG measurements}

To illustrate the OE retrieval and its difference from the MF method, we perform retrievals for an AVIRIS-NG measurement made on 4 September 2014 (ang20140904t204546) in Bakersfield, CA, as shown in Fig. 2. The location is to the west of the Kern Front oil field. This detection is a case study from the NASA-ESA $\mathrm{CO}_{2}$ and MEthane eXperiment (COMEX) campaign in California during June and August-September 2014, which includes airborne in situ, airborne non-imaging remote sensing, and ground-based in situ instruments to provide a real-time remote detection and measurement for $\mathrm{CH}_{4}$ plumes released from anthropogenic sources. An RGB image of flight data is displayed in Fig. 2a; the emission source is a pump jack, as described in Thompson et al. (2015). Figure $2 b$ presents results from the MF method, which shows that the $\mathrm{CH}_{4}$ plume disperses downwind and has a maximum enhancement value of about $2800 \mathrm{ppm} \times \mathrm{m}$. Some artifacts caused by surfaces with strong absorption in the $2100-2500 \mathrm{~nm}$ wavelength range, such as oil-based paints or roofs with calcite as a component (Thorpe 
Table 2. Optical properties of three aerosol mixture models (WCRP, 1986).

\begin{tabular}{llrrr}
\hline & & Continental & Maritime & Urban/industrial \\
\hline \multirow{3}{*}{ Aerosol component } & Dust-like & $70 \%$ & & $17 \%$ \\
\cline { 2 - 5 } & Water soluble & $29 \%$ & $5 \%$ & $61 \%$ \\
\cline { 2 - 5 } & Oceanic & & $95 \%$ & \\
\cline { 2 - 5 } & Soot & $1 \%$ & & $22 \%$ \\
\hline SSA & & 0.746 & 0.966 & 0.314 \\
\hline$g$ & & 0.764 & 0.810 & 0.586 \\
\hline
\end{tabular}

et al., 2013), also produce large $\alpha$ values in the MF method; these can be removed by an optimization method such as the columnwise MF technique (Thompson et al., 2015).

Figure 3 displays the measured radiance (a) before normalization and (b) after normalization, corresponding to two detector elements (in plume and out of plume). Every element is a cross-track spatial location. The normalization is done by calculating the ratio of the radiance to the maximum value across the spectral range, such that the values fall between 0 and 1 . This is a first-order correction for the effects of surface albedo. Comparing the measured spectrum in plume to that out of plume, there is obvious enhancement of $\mathrm{CH}_{4}$ that is particularly evident in the normalized radiance. $\mathrm{CH}_{4}$ is the main absorber in the $2100-2500 \mathrm{~nm}$ wavelength range, and $\mathrm{H}_{2} \mathrm{O}$ is the major interfering gas. Figure $3 \mathrm{~b}$ indicates the absorption peaks due to $\mathrm{H}_{2} \mathrm{O}$ and $\mathrm{CH}_{4}$.

We choose the plume center with 500 elements to illustrate results obtained using the MF and OE methods. The former evaluates the $\mathrm{CH}_{4} \alpha$ value compared to the background $\mathrm{CH}_{4}$ concentration, while the latter retrieves $\mathrm{XCH}_{4}$. In the MF method, the background covariance matrix $\boldsymbol{\Sigma}$ and mean radiance $\mu$ are drawn from a reference region close to the $\mathrm{CH}_{4}$ emission source. These are shown in Fig. 2, where the dashed green box denotes the reference region and the source is located within the solid red box. In the OE method, results are shown as a multiplicative scaling factor compared to a typical $\mathrm{XCH}_{4}$ background of $1.822 \mathrm{ppm}$. This value is the globally averaged marine surface annual mean for 2014 (Ed Dlugokencky, NOAA/GML, 2020, https://www. esrl.noaa.gov/gmd/ccgg/trends_ch4/, last access: 27 November 2020), the year corresponding to the AVIRIS-NG measurement being studied. We use the accurate and numerically efficient two-stream-exact-single-scattering (2S-ESS) RT model (Spurr and Natraj, 2011). This forward model is different from a typical two-stream model in that the twostream approximation is used only to calculate the contribution of multiple scattering to the radiation field. Single scattering is treated in a numerically exact manner using all moments of the phase function. This model has been used for remote sensing of greenhouse gases and aerosols (Xi et al., 2015; Zhang et al., 2015, 2016; Zeng et al., 2017,
2018). Aerosols are neither included in the forward model nor retrieved in this analysis. The surface albedo is set to a wavelength-independent value of 0.5 .

Results from the two retrieval methods reveal a similar $\mathrm{CH}_{4}$ plume shape (Fig. 4), especially for elements with high $\mathrm{CH}_{4}$ enhancement. However, larger differences in $\mathrm{CH}_{4}$ concentrations are evident in the OE retrievals (Fig. 4b). Since radiance normalization reduces the impact of surface albedo and aerosols are not included in either retrieval, this might be due to the fact that, in the $\mathrm{OE}$ method, $\mathrm{H}_{2} \mathrm{O}$ and $\mathrm{CH}_{4}$ are simultaneously retrieved; the $\mathrm{CH}_{4}$ retrieval has added uncertainty due to overlapping absorption features between these two gases. The large maximum value of about 3000 in the MF method also contributes to a reduction in relative contrast. While these results provide heuristic information about the relative performance of the two retrieval techniques, it is difficult to compare the $\mathrm{CH}_{4}$ enhancement directly between the two methods since the background $\mathrm{CH}_{4}$ concentration used in the MF method cannot be quantified exactly. Further, evaluating retrieval biases due to ignoring aerosol scattering is not trivial when real measurements are used. Therefore, we simulate synthetic spectra (see Sect. 4) using the 2S-ESS RT model to study the impacts of aerosol scattering as a function of different geophysical parameters by varying them in a systematic manner.

\section{Aerosol impact analysis}

\subsection{Synthetic spectra}

In a real AVIRIS-NG observation, the exact column concentration of $\mathrm{CH}_{4}$ cannot be controlled. However, synthetic simulations allow us to manipulate parameters such as $\mathrm{CH}_{4}$ concentration, surface albedo, AOD, $g$, and SSA and thereby test aerosol impacts on $\mathrm{CH}_{4}$ retrievals. The 2S-ESS RT model is used to simulate the AVIRIS-NG spectral radiance. In this model, a prior atmospheric profile with 70 layers from the surface up to $70 \mathrm{~km}$ is derived from National Center for Environmental Prediction reanalysis data (Kalnay et al., 1996); absorption coefficients for all relevant gases are obtained from the HITRAN database (Rothman et al., 2009). 

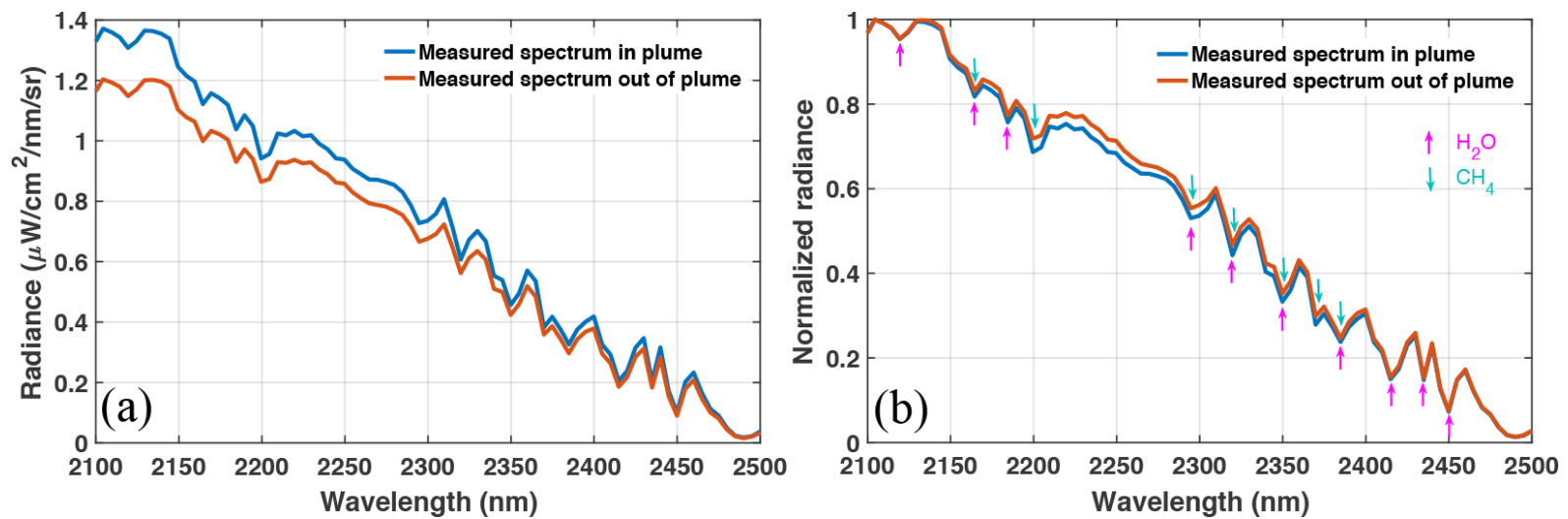

Figure 3. (a) Real radiance and (b) normalized radiance at cross-track detector elements (in and out of plume) from the sample AVIRIS-NG measurement. The colored arrows in (b) show the main absorption features due to $\mathrm{H}_{2} \mathrm{O}$ (purple) and $\mathrm{CH}_{4}$ (green).
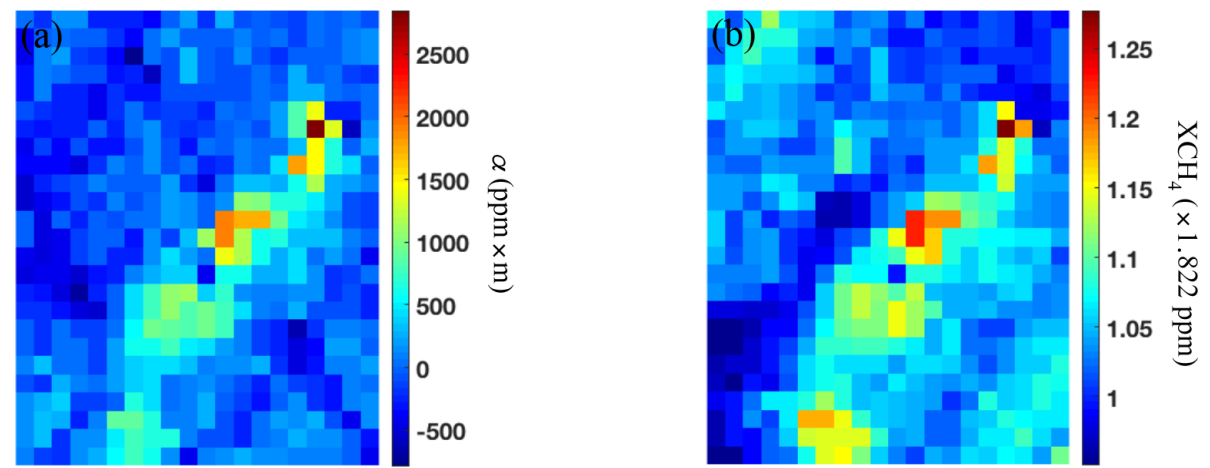

Figure 4. Retrieval image for the plume center (500 elements) based on the (a) MF method and (b) OE method.

Monochromatic RT calculations are performed at a spectral resolution of $0.5 \mathrm{~cm}^{-1}$; the radiance spectrum is then convolved using a Gaussian instrument line shape function with a wavelength-dependent full width at half maximum (FWHM) from a calibrated AVIRIS-NG data file. The signalto-noise ratio (SNR) is set to be 300 , with Gaussian white noise added. This procedure results in a wavelength grid with a resolution of about $5 \mathrm{~nm}$. The spectral wavelength range used to retrieve $\mathrm{CH}_{4}$ is from 2100 to $2500 \mathrm{~nm}$.

The additional atmospheric and geometric variables included in the model are listed in Table 3, which are held constant unless otherwise mentioned. The observation geometry parameters are taken from a real AVIRIS-NG measurement. Recent AVIRIS-NG flight campaigns have sensor heights ranging from 0.43 to $3.8 \mathrm{~km}$; we choose a value of $1 \mathrm{~km}$, the same as the highest level where aerosol is present in our simulations. The influence of AOD on $\mathrm{CH}_{4}$ retrieval as a function of SSA and $g$ is analyzed in Sect. 4.3; in all other cases, SSA and $g$ are held constant at 0.95 and 0.75 , respectively, which is representative of aerosols in the Los Angeles region (Zhang et al., 2015).
Table 3. Inputs for the 2S-ESS model simulation.

\begin{tabular}{ll}
\hline Attribute & Values \\
\hline Sensor height & $1 \mathrm{~km}$ \\
View zenith angle & $11.91^{\circ}$ \\
Solar zenith angle & $30.75^{\circ}$ \\
Relative azimuth angle & $22.87^{\circ}$ \\
Aerosol loading region & surface to $1 \mathrm{~km}$ \\
SSA & 0.95 \\
$g$ & 0.75 \\
\hline
\end{tabular}

\subsection{Aerosol impact in the MF method}

We simulate synthetic spectra at different AOD, surface albedo, and $\mathrm{CH}_{4}$ concentration values; use the MF method to obtain the $\mathrm{CH}_{4}$ enhancement; and compare differences in $\alpha$ between scenarios without and with aerosol. The covariance matrix and background mean radiance are calculated from a simulated zero AOD background with surface albedos from 0.1 to 0.5 and $\mathrm{XCH}_{4}$ set at the typical background value of $1.822 \mathrm{ppm}$ used in Sect. 3. Figure 5a shows the enhancement value as a function of $\mathrm{XCH}_{4}$. As the $\mathrm{CH}_{4}$ concentration in- 
creases, the enhancement value obtained by the MF method at first increases approximately linearly. However, the absorption changes in a nonlinear fashion with concentration, whereas the MF method applies a linear formalism to the change. Therefore, the enhancement value (which is correlated with the absorption signature) also shows a deviation from linear behavior at larger $\mathrm{XCH}_{4}$. Two aerosol scenarios $(\mathrm{AOD}=0,0.3)$ are compared in Fig. 5a, which reveals that the effect of aerosol loading is similar to an underestimation of $\mathrm{CH}_{4}$ in the retrieval. The underestimation, which is due to the shielding of $\mathrm{CH}_{4}$ absorption below the aerosol layer and the fact that multiple-scattering (MS) effects between the aerosol and the surface are ignored, is clearly shown in Fig. 5b, where the enhancement value for fixed $\mathrm{CH}_{4}$ concentration (same concentration as the background) decreases from $0 \mathrm{ppm} \times \mathrm{m}$ to $-1532 \mathrm{ppm} \times \mathrm{m}$ with increasing AOD. To clarify the impact of AOD at different surface albedo values, zoomed-in versions of $\alpha$ as a function of $\mathrm{XCH}_{4}$ are presented in Fig. 5c-f. For the AOD $=0$ scenario, the results are independent of surface albedo. This is because there are no MS effects between the surface and the atmosphere (Rayleigh scattering is negligible in the retrieval wavelength range) when there is no aerosol loading. For the scenarios with aerosol loading, the dispersion in the zero-enhancement $\mathrm{XCH}_{4}$ value between different surface albedos indicates that results from the MF method are biased more at large AOD and surface albedo values (Fig. 5d-f). This is a consequence of increased multiple scattering between the aerosol layer and the surface that is not accounted for by the retrieval algorithm. The maximum bias value is close to $-700 \mathrm{ppm} \times \mathrm{m}$ (equivalent to $-0.06 \times 1.822 \mathrm{ppm}$ relative to the background concentration of $1.0 \times 1.822 \mathrm{ppm}$ ) for an AOD of 0.3 and surface albedo of 0.5 (Fig. 5f). The implication of these results is that accurate knowledge of the surface albedo is important for MF retrievals, especially when the aerosol loading is large.

A quantitative analysis of underestimation of $\mathrm{CH}_{4}$ concentration due to aerosol scattering is presented in Fig. 6. The color bar shows the $\alpha$ bias - which is defined as the difference between the enhancement value without aerosol (true $\alpha$ value) and that with aerosol - for different $\mathrm{CH}_{4}$ concentrations, surface albedos, and AODs. A positive bias means that $\mathrm{CH}_{4}$ is underestimated. The $\alpha$ bias increases with increasing surface albedo and AOD, reaching a maximum value of about $700 \mathrm{ppm} \times \mathrm{m}$ for the simulated cases. However, it is interesting that the bias decreases with increasing $\mathrm{CH}_{4}$ concentration, which is different from the results obtained by the $\mathrm{OE}$ method (discussed in Sect. 4.3). This surprising behavior is a direct consequence of the physical basis of the MF method. The rate of increase in enhancement becomes smaller as $\mathrm{XCH}_{4}$ becomes larger (Fig. 5a). Therefore, at higher $\mathrm{XCH}_{4}$ values, the addition of aerosols (which has a similar effect as a reduction in $\mathrm{XCH}_{4}$ ) results in a lower reduction in enhancement compared to that at lower $\mathrm{XCH}_{4}$ values, resulting in a net decrease in the enhancement bias.

\subsection{Aerosol impact in the OE method}

For the simulation of the synthetic spectra, we assume nonzero aerosol loading below $1 \mathrm{~km}$ elevation. The $\mathrm{OE}$ method is then used to perform retrievals using the same configuration (including, in particular, the same surface albedo) except that AOD is set to zero. This approach is similar to neglecting aerosol scattering in the $\mathrm{CH}_{4}$ retrieval; the retrieval bias is defined as the difference between the true $\mathrm{XCH}_{4}$ in the simulation and the retrieved value (positive values refer to underestimation). First, we study the retrieval bias caused by different aerosol types and mixtures. Figure 7 a shows $\mathrm{CH}_{4}$ retrieval biases as a function of SSA and $g$; surface albedo and AOD are kept constant at 0.3 and $\mathrm{XCH}_{4}$ is assumed to be $1.0 \times 1.822 \mathrm{ppm}$. The retrieval bias increases with SSA and decreases with $g$, with a maximum bias ratio (ratio of retrieval bias to the true value) of about $20 \%$. This behavior can be explained as follows. At higher SSA values, there are more MS effects (that are ignored in the retrieval). On the other hand, larger values of $g$ imply greater anisotropy of scattering (preference for forward scattering), leading to a reduction in MS effects. Since the retrieval bias is large for high SSA and low $g$, the water-soluble aerosol type (Table 1) and the maritime aerosol model (Table 2) can be expected to induce greater biases in the retrieval. In order to compare the impacts of SSA and $g$ in further detail, retrieval results due to a $\pm 5 \%$ change in SSA and $g$ for the three aerosol models from Table 2 are shown in Fig. $7 b$ and c. Note that for the maritime aerosol model, the SSA is set to 0.999 for the $+5 \%$ scenario to ensure physicality. It is clear that (1) the maritime aerosol model induces larger retrieval biases than the other aerosol types, and (2) the retrieval results are more sensitive to changes in $g$ than those in SSA.

We then simulate synthetic spectra for different values of $\mathrm{CH}_{4}$ concentration, surface albedo, and AOD. The impacts of aerosol scattering on the retrievals for these scenarios are demonstrated in Fig. 8. Figure 8a shows a $5 \times 5$ panel of boxes. Within each box, $\mathrm{XCH}_{4}$ is constant, while surface albedo increases from top to bottom and AOD increases from left to right. The variation in $\mathrm{XCH}_{4}$ across the boxes is shown in Fig. 8b. We also show a zoomed-in plot of the bottom right box $\left(\mathrm{XCH}_{4}=5.8 \times 1.822 \mathrm{ppm}\right)$ in Fig. $8 \mathrm{c}$, which illustrates the AOD and surface albedo changes within a box. These changes are identical for all boxes. Figure $8 \mathrm{a}$ indicates that OE retrievals produce larger $\mathrm{CH}_{4}$ biases at higher $\mathrm{XCH}_{4}$ values, in contrast with MF results. In addition, it is evident that the retrieved $\mathrm{CH}_{4}$ bias increases with increasing AOD. The $\mathrm{CH}_{4}$ bias induced by differences in the surface albedo is not as large as that due to AOD variations, but surface albedo effects are noticeable at large AOD. Figure 8d shows the sensitivity of retrieval biases to changes in AOD and surface albedo, again demonstrating the greater impact of AOD than surface albedo in the retrieval.

The effects of changing the a priori, a priori error, and RT simulation spectral resolution on the retrieved $\mathrm{XCH}_{4}$ are 

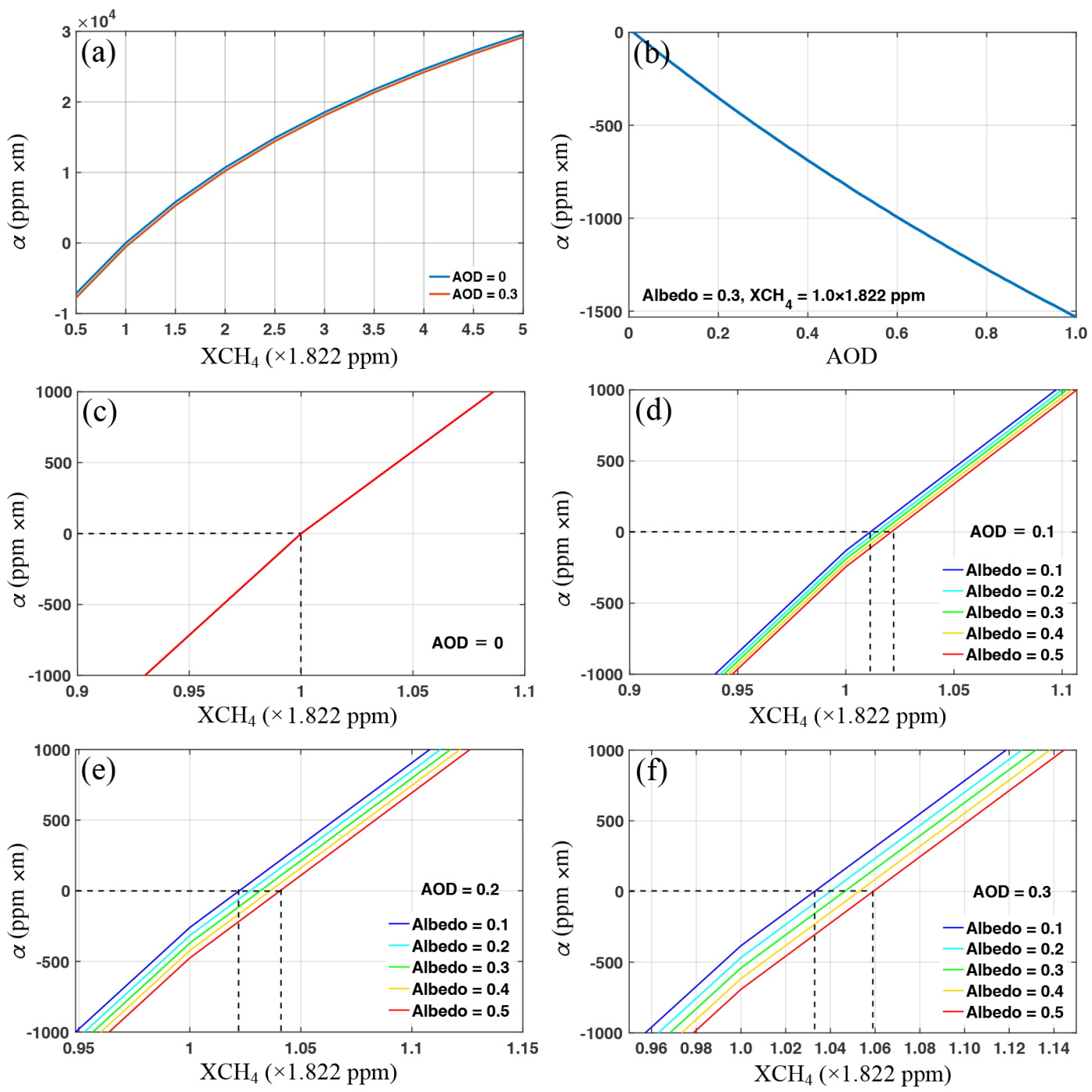

Figure 5. (a) $\alpha$ as a function of $\mathrm{XCH}_{4}$ for $\mathrm{AOD}=0$ and $\mathrm{AOD}=0.3$ (surface albedo $=0.3$ ). (b) $\alpha$ as a function of $\mathrm{AOD}(\mathrm{XCH} 4=1.0 \times$ $1.822 \mathrm{ppm}$, surface albedo $=0.3)$. Zoomed-in versions of $\alpha$ as a function of $\mathrm{XCH}_{4}$ for different surface albedos $(0.1-0.5)$, where $(\mathbf{c}) \mathrm{AOD}=0$, (d) $\mathrm{AOD}=0.1,(\mathbf{e}) \mathrm{AOD}=0.2$, and (f) $\mathrm{AOD}=0.3$.
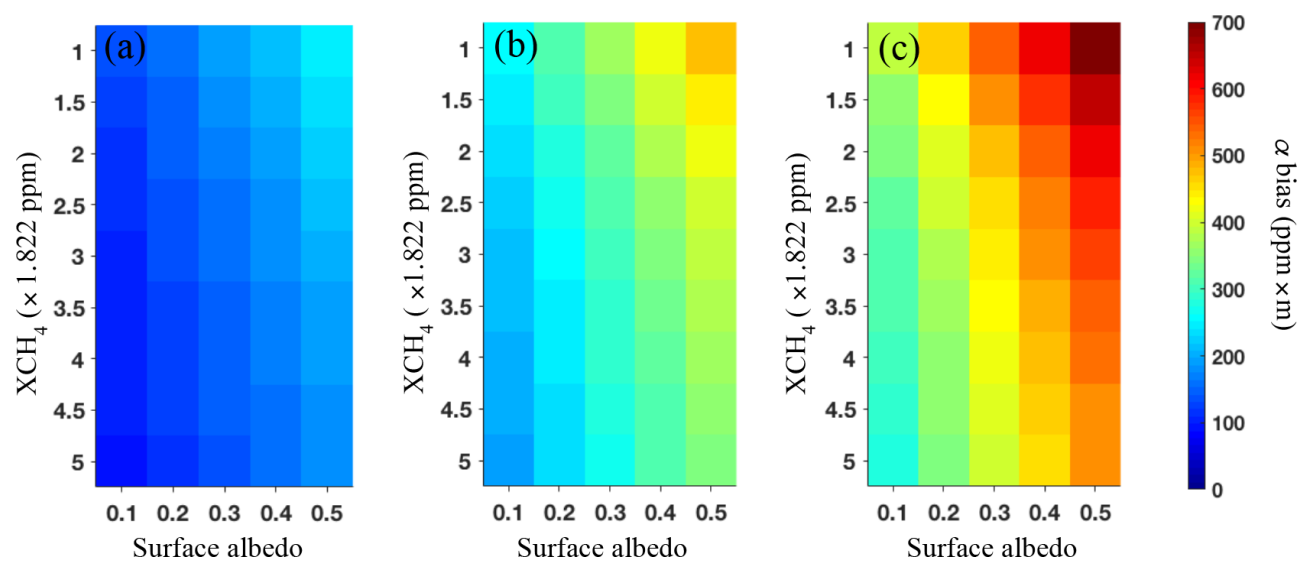

Figure 6. Bias in $\alpha$ as a function of $\mathrm{XCH}_{4}$ and surface albedo for (a) $\mathrm{AOD}=0.1$, (b) $\mathrm{AOD}=0.2$, and (c) $\mathrm{AOD}=0.3$. 

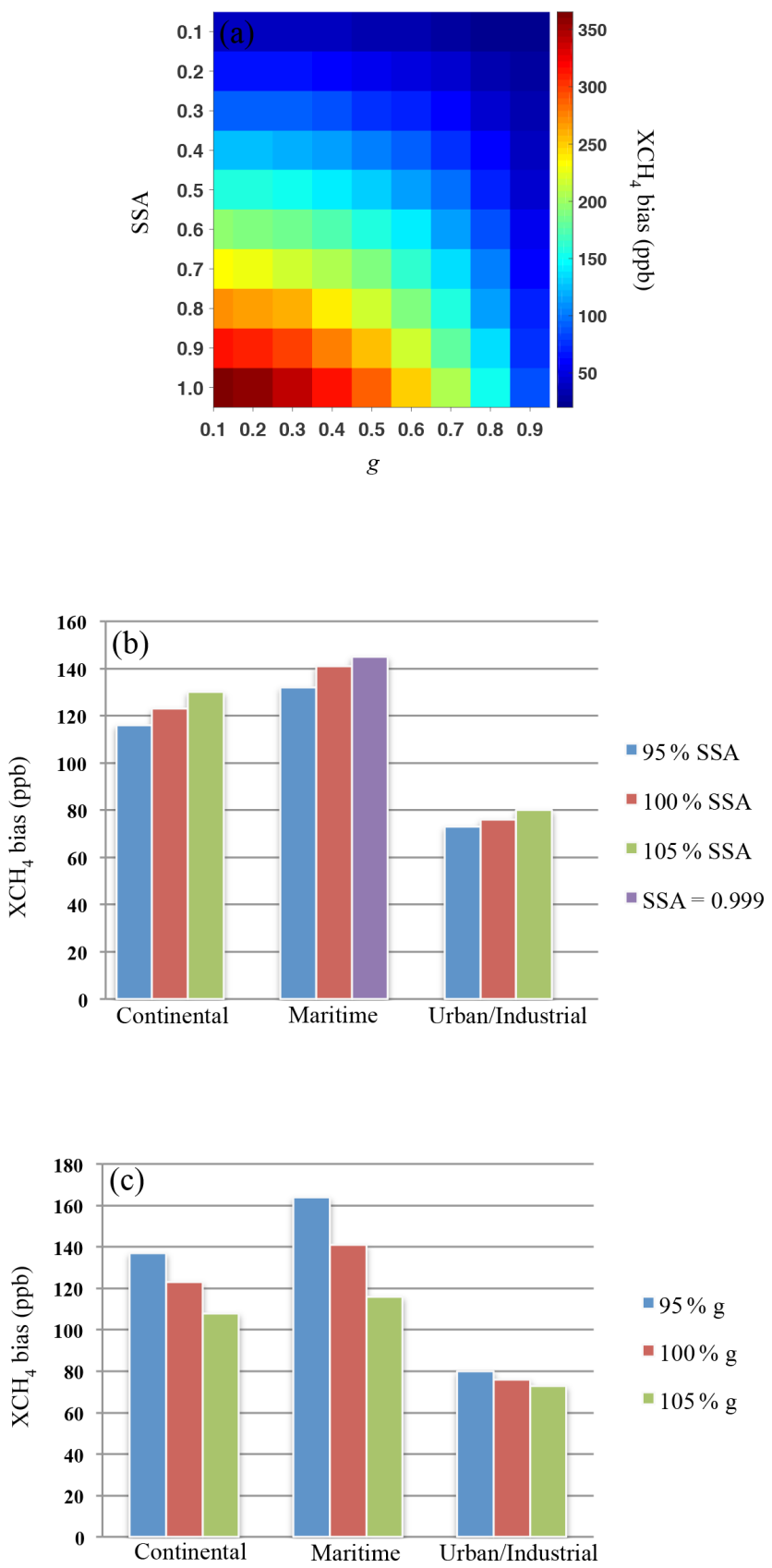

Figure 7. (a) $\mathrm{CH}_{4}$ retrieval biases for different values of $g$ and SSA. Surface albedo, $\mathrm{AOD}=0.3, \mathrm{XCH}_{4}=1.0 \times 1.822 \mathrm{ppm}$. (b) $\mathrm{CH}_{4}$ retrieval biases for a $\pm 5 \%$ change in SSA for the three aerosol mixture models. (c) Same as (b), but for a $\pm 5 \%$ change in $g$.

shown in Fig. 9. For these calculations, the other parameters are set as follows: $\mathrm{SSA}=0.95, g=0.75, \mathrm{AOD}=1.0$, surface albedo $=0.5$, and true $\mathrm{XCH}_{4}=5.8 \times 1.822 \mathrm{ppm}$. The parameters were chosen to correspond to the scenario with the largest retrieval bias in Fig. 8c (bottom right box in Fig. 8c). Figure 9a shows that the retrieved $\mathrm{XCH}_{4}$ changes by about $9 \mathrm{ppb}$ as the a priori changes from half to twice the true $\mathrm{XCH}_{4}$ value. Similarly, the $\mathrm{XCH}_{4}$ difference is less

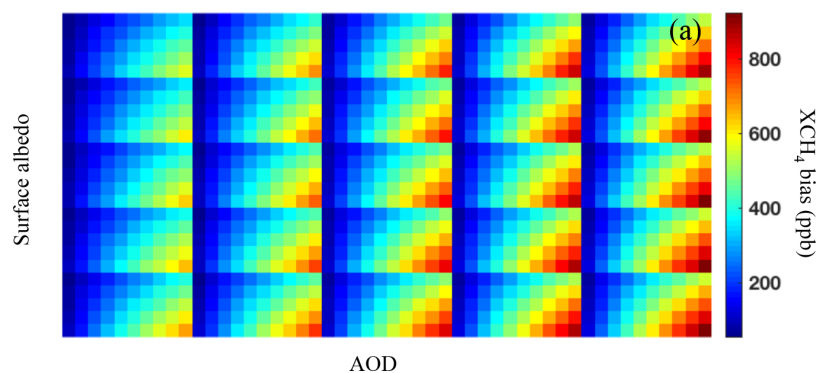

\begin{tabular}{|c|c|c|c|c|}
\hline 1 & 2 & 3 & 4 & 5 (b) \\
\hline 1.2 & 2.2 & 3.2 & 4.2 & 5.2 \\
\hline 1.4 & 2.4 & 3.4 & 4.4 & 5.4 \\
\hline 1.6 & 2.6 & 3.6 & 4.6 & 5.6 \\
\hline 1.8 & 2.8 & 3.8 & 4.8 & 5.8 \\
\hline
\end{tabular}
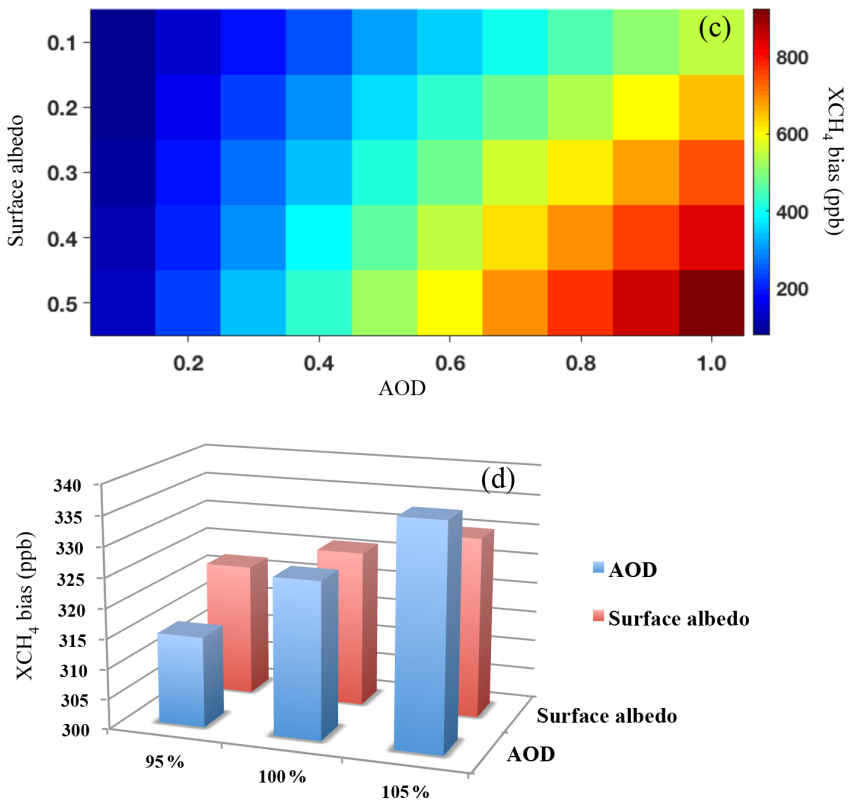

Figure 8. (a) $\mathrm{CH}_{4}$ retrieval biases for different values of $\mathrm{XCH}_{4}$, $\mathrm{AOD}$, and surface albedo. $g=0.75$; $\mathrm{SSA}=0.95$. (b) $\mathrm{XCH}_{4}$ for each box in (a). (c) Zoomed-in plot of bottom right box $\left(\mathrm{XCH}_{4}=\right.$ $5.8 \times 1.822 \mathrm{ppm}$ ). The $x$ and $y$ axes show the variation in AOD and surface albedo, respectively. These changes are identical for every box in (a). (d) $\mathrm{CH}_{4}$ retrieval biases for a $\pm 5 \%$ change in AOD and surface albedo from a base value of $0.3(g=0.75, \mathrm{SSA}=0.95$, $\left.\mathrm{XCH}_{4}=5.8 \times 1.822 \mathrm{ppm}\right)$.

than $4 \mathrm{ppb}$ when the a priori error changes from 0.05 to 0.5 (Fig. 9b). Compared to the bias of about $923 \mathrm{ppb}$ induced by neglecting aerosol scattering for this scenario, it is clear that the impacts of the a priori and a priori error are very small. The effect of spectral resolution is larger, but $\mathrm{XCH}_{4}$ still changes by only about $100 \mathrm{ppb}$ when the spectral resolution is changed from 0.5 to $0.1 \mathrm{~cm}^{-1}$ (Fig. 9c). 

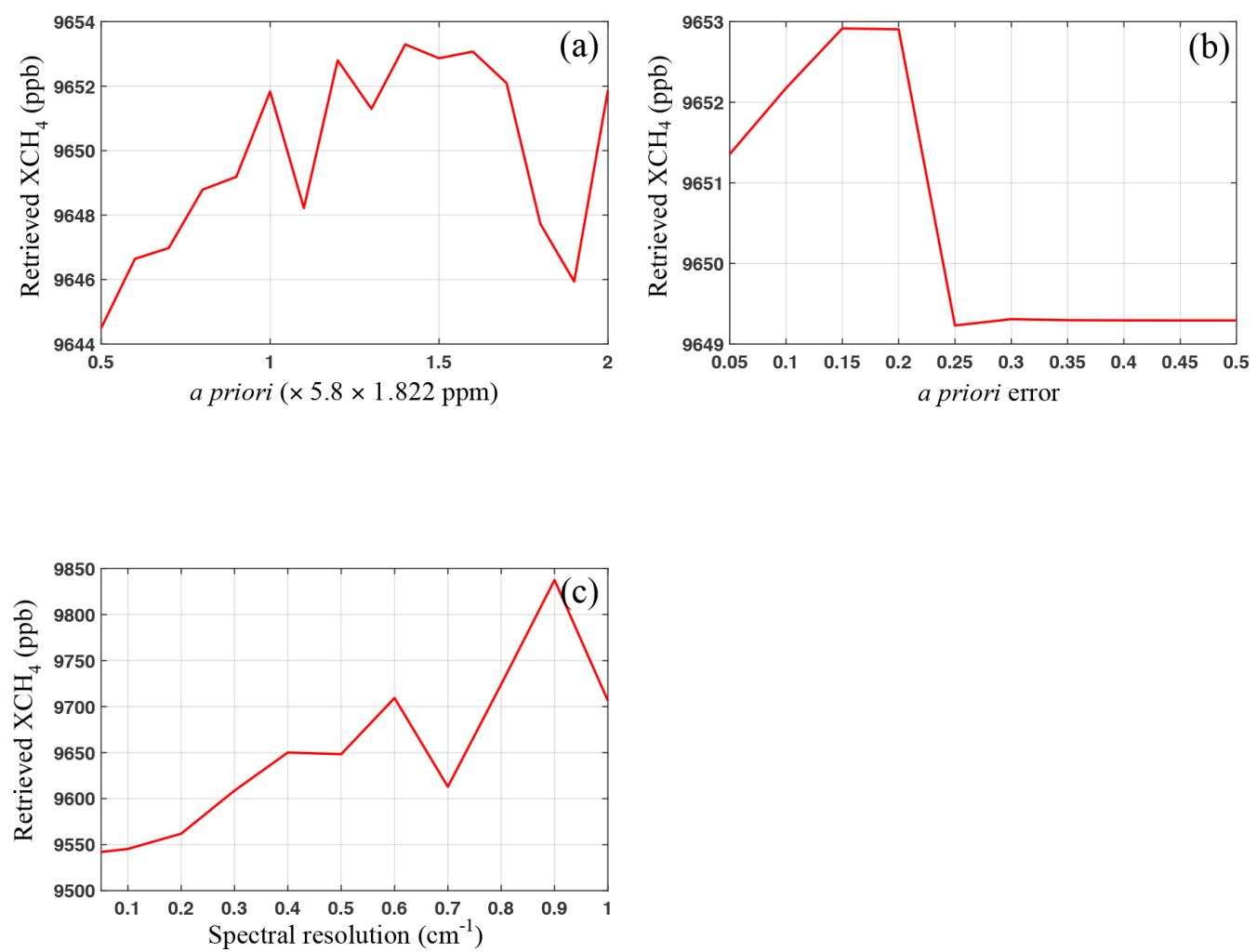

Figure 9. Retrieved $\mathrm{XCH}_{4}$ for different values of (a) a priori (a priori error $=0.2$ ), (b) a priori error $(\mathrm{a}$ priori $=5.5 \times 1.822 \mathrm{ppm})$, and (c) spectral resolution. $g=0.75, \mathrm{SSA}=0.95, \mathrm{AOD}=1.0$, surface albedo $=0.5, \mathrm{XCH}_{4}=5.8 \times 1.822 \mathrm{ppm}$.
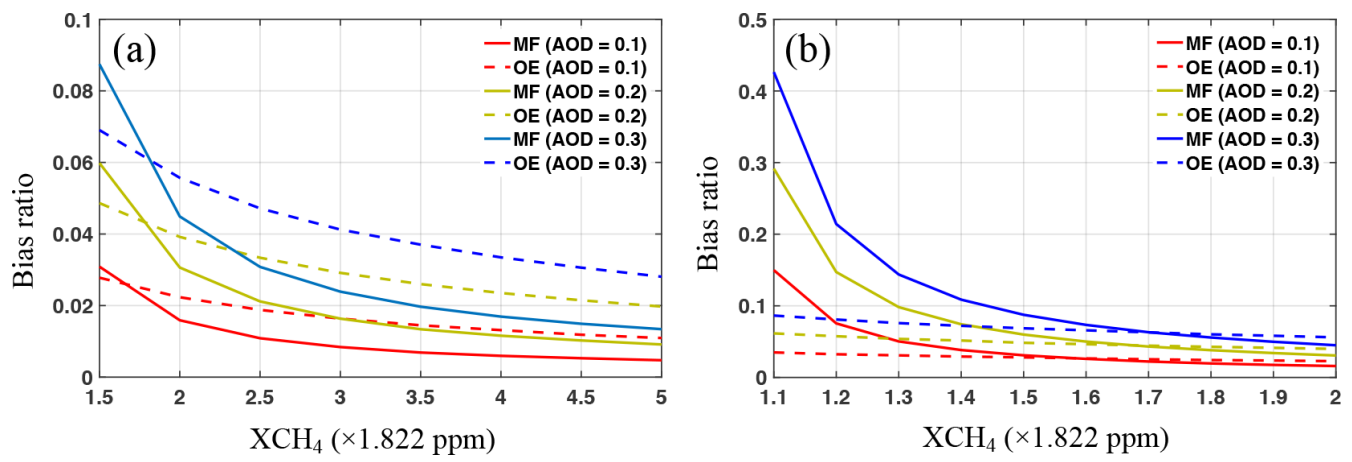

Figure 10. (a) Bias ratio as a function of $\mathrm{CH}_{4}$ concentration for the two retrieval techniques, where the $\mathrm{XCH}_{4}$ ranges from 1.5 to 5 $(\times 1.822 \mathrm{ppm})$. (b) Same as (a), but for $\mathrm{XCH}_{4}$ ranging from 1.1 to $2(\times 1.822 \mathrm{ppm})$. Surface albedo is set to 0.3 for all cases; results for the MF and $\mathrm{OE}$ methods are shown by solid and dashed lines, respectively.

\subsection{Comparison of the two retrieval techniques}

Figure 10 presents the bias ratios for the two retrieval techniques at different AODs (surface albedo $=0.3$ ). In the MF method, the bias ratio is defined as the ratio of the bias to the true value of $\alpha$. On the other hand, in the OE method, it is the ratio of the bias to the true $\mathrm{XCH}_{4}$. From Fig. 10 it is clear that the bias ratio decreases with increasing $\mathrm{CH}_{4}$ concentration and has higher values at larger AODs. The bias ratio for the MF method $(1.3 \%-4.5 \%)$ is up to $53.6 \%$ less than that for the $\mathrm{OE}$ method $(2.8 \%-5.6 \%)$ for $\mathrm{AOD}=0.3$ when the $\mathrm{CH}_{4}$ concentration is high (2-5 times typical background values). On the other hand, the $\mathrm{OE}$ method performs better when enhancements are small and $\mathrm{XCH}_{4}$ is close to the background value. For example, the bias ratio for the MF method has a high value of about $42.6 \%$ at $\mathrm{AOD}=0.3$ for a $10 \%$ enhancement $\left(\mathrm{XCH}_{4}=1.1 \times 1.822 \mathrm{ppm}\right)$; the $\mathrm{OE}$ value for the same scenario is $8.6 \%$. For scenarios where scattering is ignored, the two retrieval techniques seem to be complementary, with differing utilities for different enhancements. 
On the other hand, when RT models that account for scattering effects are employed, the MF technique is suboptimal. Further, MF retrievals rely on accurate characterization of the surface albedo, especially when the aerosol loading is large. Finally, the MF method does not retrieve concentrations, which are necessary to infer fluxes. Therefore, the OE technique is in general superior due to its ability to support simultaneous retrieval of aerosols, surface albedo, and $\mathrm{CH}_{4}$ concentration.

\section{Summary and discussion}

Remote sensing measurements from airborne and satellite instruments are widely used to detect $\mathrm{CH}_{4}$ emissions. In our study, the traditional MF and the OE methods are used to quantify the effects of aerosol scattering on $\mathrm{CH}_{4}$ retrievals based on simulations of AVIRIS-NG measurements. The results show that the retrieval biases increase with increasing AOD and surface albedo for both techniques. In the OE method the biases increase with increasing $\mathrm{CH}_{4}$ concentration and SSA, but decrease with increasing aerosol asymmetry parameter. The $\mathrm{CH}_{4}$ retrieval bias increases with increasing $\mathrm{XCH}_{4}$ in the $\mathrm{OE}$ method but decreases for the same scenario in the MF method. The surprising MF trend is attributed to the inability of the MF method to treat nonlinear absorption effects at high $\mathrm{XCH}_{4}$ values. We also present bias ratios for the two techniques. The MF method shows smaller bias ratios at large $\mathrm{CH}_{4}$ concentrations than the $\mathrm{OE}$ method; it is, therefore, the optimal method to detect strong $\mathrm{CH}_{4}$ emission sources when scattering effects can be ignored in the retrieval. For the same retrieval scenario, the OE method seems to be more suitable for detecting diffuse sources. Further, the MF method relies on a comparison with the background $\mathrm{CH}_{4}$ concentration. It is difficult to get an accurate estimate of the background $\mathrm{XCH}_{4}$ value in polluted atmospheric environments. In contrast, the $\mathrm{OE}$ method provides retrievals based solely on the atmospheric scenario of interest; $\mathrm{CH}_{4}$, aerosols, and surface albedo can be simultaneously inferred. Therefore, when scattering effects need to be considered, the OE method is the appropriate choice. Indeed, the MF method was intended for plume detection. OE enables accurate quantification of $\mathrm{XCH}_{4}$ in the presence of aerosol scattering.

This study focused on a comparison of retrieval techniques. It is also important to accurately represent the physics of atmospheric RT, especially for scenarios with significant aerosol scattering. RT models traditionally used in retrievals of imaging spectroscopic data use simplified radiation schemes and predefined aerosol models, which may introduce inaccuracy in the representation of atmospheric physics. The 2S-ESS model provides the capability to quantify aerosol impacts on $\mathrm{CH}_{4}$ retrieval for different aerosol types, optical depths, and layer heights. In future work, we will compare retrievals using the 2 S-ESS model against those from other commonly used models such as MODTRAN. We will also evaluate the impact of varying instrument spectral resolution and signal-to-noise ratio for simultaneous retrieval of $\mathrm{CH}_{4}$, surface albedo and AOD. This will be relevant for the design of imaging spectrometers for planned future missions such as the NASA Surface Biology and Geology (SBG) mission.

Data availability. The code and data are available from the authors upon request.

Author contributions. VN conceived the work, provided the radiative transfer and aerosol models, supervised $\mathrm{YH}$, and assisted with manuscript preparation. YH designed and performed the retrievals, analyzed the results, and prepared the original manuscript. ZCZ contributed to retrieval setup and assisted with analysis of the results. PK provided valuable inputs into the science of $\mathrm{CH}_{4}$ remote sensing. YLY supervised YH and participated in the evaluation of the retrieval results and intercomparison. All listed authors contributed to the review and editing of this paper.

Competing interests. The authors declare that there is no conflict of interest.

Acknowledgements. A portion of this research was carried out at the Jet Propulsion Laboratory, California Institute of Technology, under a contract with the National Aeronautics and Space Administration (80NM0018D0004). The authors gratefully acknowledge the insightful and constructive comments from the two anonymous reviewers, which improved the clarity and quality of the manuscript and elevated the significance of the work beyond the original expectation.

Financial support. This research has been supported by the NASA "Utilization of Airborne Visible/Infrared Imaging Spectrometer Next Generation Data from an Airborne Campaign in India" program (grant no. NNH16ZDA001N-AVRSNG) and the Jet Propulsion Laboratory Research and Technology Development program. PK was funded by the Japan Society for the Promotion of Science International Research Fellow Program.

Review statement. This paper was edited by Jun Wang and reviewed by two anonymous referees.

\section{References}

Alvarez, R. A., Zavala-Araiza, D., Lyon, D. R., Allen, D. T., Barkley, Z. R., Brandt, A. R., Davis, K. J., Herndon, S. C., Jacob, D. J., Karion, A., Kort, E. A., Lamb, B. K., Lauvaux, T., Maasakkers, J. D., Marchese, A. J., Omara, M., Pacala, S. W., Peischl, J., Robinson, A. L., Shepson, P. B., Sweeney, C., Townsend-Small, A., Wofsy, S. C., and 
Hamburg, S. P.: Assessment of methane emissions from the U.S. oil and gas supply chain, Science, 361, 186-188, https://doi.org/10.1126/science.aar7204, 2018.

Archer, D.: Methane hydrate stability and anthropogenic climate change, Biogeosciences, 4, 521-544, https://doi.org/10.5194/bg4-521-2007, 2007.

Bradley, E. S., Leifer, I., Roberts, D. A., Dennison, P. E., and Washburn, L.: Detection of marine methane emissions with AVIRIS band ratios, Geophys. Res. Lett., 38, L10702, https://doi.org/10.1029/2011GL046729, 2011.

Bubier, J. L. and Moore, T. R.: An ecological perspective on methane emissions from northern wetlands, Trends Ecol. Evol., 9, 460-464, https://doi.org/10.1016/0169-5347(94)903093, 1994.

Buchwitz, M., Reuter, M., Bovensmann, H., Pillai, D., Heymann, J., Schneising, O., Rozanov, V., Krings, T., Burrows, J. P., Boesch, H., Gerbig, C., Meijer, Y., and Löscher, A.: Carbon Monitoring Satellite (CarbonSat): assessment of atmospheric $\mathrm{CO}_{2}$ and $\mathrm{CH}_{4}$ retrieval errors by error parameterization, Atmos. Meas. Tech., 6, 3477-3500, https://doi.org/10.5194/amt-6-3477-2013, 2013.

Butz, A., Galli, A., Hasekamp, O., Landgraf, J., Tol, P., and Aben, I.: TROPOMI aboard Sentinel-5 Precursor: Prospective performance of $\mathrm{CH}_{4}$ retrievals for aerosol and cirrus loaded atmospheres, Remote Sens. Environ., 120, 267-276, https://doi.org/10.1016/j.rse.2011.05.030, 2012.

Butz, A., Orphal, J., Checa-Garcia, R., Friedl-Vallon, F., von Clarmann, T., Bovensmann, H., Hasekamp, O., Landgraf, J., Knigge, T., Weise, D., Sqalli-Houssini, O., and Kemper, D.: Geostationary Emission Explorer for Europe (G3E): mission concept and initial performance assessment, Atmos. Meas. Tech., 8, 47194734, https://doi.org/10.5194/amt-8-4719-2015, 2015.

Clerbaux, C., Hadji-Lazaro, J., Turquety, S., Mégie, G., and Coheur, P.-F.: Trace gas measurements from infrared satellite for chemistry and climate applications, Atmos. Chem. Phys., 3, 14951508, https://doi.org/10.5194/acp-3-1495-2003, 2003.

Dennison, P. E., Thorpe, A. K., Pardyjak, E. R., Roberts, D. A., Qi, Y., Green, R. O., Bradley, E. S., and Funk, C. C.: High spatial resolution mapping of elevated atmospheric carbon dioxide using airborne imaging spectroscopy: Radiative transfer modeling and power plant plume detection, Remote Sens. Environ., 139, 116129, https://doi.org/10.1016/j.rse.2013.08.001, 2013.

Etiope, G., Feyzullayev, A., and Baciu, C. L.: Terrestrial methane seeps and mud volcanoes: A global perspective of gas origin, Mar. Petrol. Geol., 26, 333-344, https://doi.org/10.1016/j.marpetgeo.2008.03.001, 2009.

Fishman, J. L., Iraci, L. T., Al-Saadi, J., Chance, K., Chavez, F., Chin, M., Coble, P., Davis, C., DiGiacomo, P. M., Edwards, D., Eldering, A., Goes, J., Herman, J., Hu, C., Jacob, D. J., Jordan, C., Kawa, S. R., Key, R., Liu, X., Lohrenz, S., Mannino, A., Natraj, V., Neil, D., Neu, J., Newchurch, M., Pickering, K., Salisbury, J., Sosik, H., Subramaniam, A., Tzortziou, M., Wang, J., and Wang, M.: The United States' next generation of atmospheric composition and coastal ecosystem measurements: NASA's Geostationary Coastal and Air Pollution Events (GEO-CAPE) Mission, B. Am. Meteorol. Soc., 93, 1547-1566, https://doi.org/10.1175/BAMS-D-11-00201.1, 2012.

Frankenberg, C., Platt, U., and Wagner, T.: Iterative maximum a posteriori (IMAP)-DOAS for retrieval of strongly absorbing trace gases: Model studies for $\mathrm{CH}_{4}$ and $\mathrm{CO}_{2}$ retrieval from near infrared spectra of SCIAMACHY onboard ENVISAT, Atmos. Chem. Phys., 5, 9-22, https://doi.org/10.5194/acp-5-92005, 2005.

Frankenberg, C., Meirink, J. F., Bergamaschi, P., Goede, A., P. H., Heimann, M., Körner, S., Platt, U., van Weele, M., and Wagner, T.: Satellite chartography of atmospheric methane from SCIAMACHY on board ENVISAT: Analysis of the years 2003 and 2004, J. Geophys. Res., 111, D07303, https://doi.org/10.1029/2005JD006235, 2006.

Frankenberg, C., Thorpe, A. K., Thompson, D. R., Hulley, G., Kort, E. A., Vance, N., Borchardt, J., Krings, T., Gerilowski, K., Sweeney, C., Conley, S., Bue, B. D., Aubrey, A. D., Hook, S., and Green, R. O.: Airborne methane remote measurements reveal heavy-tail flux distribution in Four Corners region, P. Natl. Acad. Sci. USA, 113, 9734-9739, https://doi.org/10.1073/pnas.1605617113, 2016.

Gambacorta, A., Barnet, C. D., Smith, N., Pierce, R. B., Smith, J. W., Spackman, J. R., and Goldberg, M.: The NPP and J1 NOAA Unique Combined Atmospheric Processing System (NUCAPS) for atmospheric thermal sounding: Recent algorithm enhancements tailored to near real time users applications, 2016 Fall Meeting, AGU, San Francisco, CA, 12-16 December 2016, Abstract IN33D-07, 2016.

Gedney, N., Cox, P. M., and Huntingford, C.: Climate feedback from wetland methane emissions, Geophys. Res. Lett., 31, L20503. https://doi.org/10.1029/2004GL020919, 2004.

Glumb, R., Davis, G., and Lietzke, C.: The TANSO-FTS-2 instrument for the GOSAT-2 greenhouse gas monitoring mission, in: 2014 IEEE Geoscience and Remote Sensing Symposium, Quebec City, QC, Canada, 13-18 July 2014, IEEE, 1238-1240, https://doi.org/10.1109/IGARSS.2014.6946656, 2014.

Green, R. O., Eastwood, M. L., Sarture, C. M., Chrien, T. G., Aronsson, M., Chippendale, B. J., Faust, J. A., Pavri, B. E., Chovit, C. J., Solis, M., Olah, M. R., and Williams, O.: Imaging spectroscopy and the Airborne Visible/Infrared Imaging Spectrometer (AVIRIS), Remote Sens. Environ., 65, 227-248, https://doi.org/10.1016/S0034-4257(98)00064-9, 1998.

He, L., Zeng, Z.-C., Pongetti, T. J., Wong, C., Liang, J., Gurney, K. R., Newman, S., Yadav, V., Verhulst, K., Miller, C. E., and Duren, R.: Atmospheric methane emissions correlate with natural gas consumption from residential and commercial sectors in Los Angeles, Geophys. Res. Lett., 46, 8563-8571, https://doi.org/10.1029/2019GL083400, 2019.

Henyey, L. G. and Greenstein, J. L.: Diffuse radiation in the galaxy, Astrophys. J., 93, 70-83, https://doi.org/10.1086/144246, 1941.

Herrero, M., Henderson, B., Havlík, P., Thornton, P. K., Conant, R. T., Smith, P., Wirsenius, S., Hristov, A. N., Gerber, P., Gill, M., Butterbach-Bahl, K., Valin, H., Garnett, T., and Shehfest, E.: Greenhouse gas mitigation potentials in the livestock sector, Nat. Clim. Change, 6, 452-461, https://doi.org/10.1038/nclimate2925, 2016.

Holmes, C. D., Prather, M. J., Søvde, O. A., and Myhre, G.: Future methane, hydroxyl, and their uncertainties: key climate and emission parameters for future predictions, Atmos. Chem. Phys., 13, 285-302, https://doi.org/10.5194/acp-13-285-2013, 2013.

Howarth, R. W.: Methane emissions and climatic warming risk from hydraulic fracturing and shale gas development: implications for policy, Energy and Emission Control Technologies, 3, 45-54, https://doi.org/10.2147/EECT.S61539, 2015. 
Howarth, R. W.: Ideas and perspectives: is shale gas a major driver of recent increase in global atmospheric methane?, Biogeosciences, 16, 3033-3046, https://doi.org/10.5194/bg-16-30332019, 2019.

Howarth, R. W., Santoro, R., and Ingraffea, A.: Methane and the greenhouse gas footprint of natural gas from shale formations, Clim. Change, 106, 679, https://doi.org/10.1007/s10584011-0061-5, 2011.

Jacob, D. J., Turner, A. J., Maasakkers, J. D., Sheng, J., Sun, K., Liu, X., Chance, K., Aben, I., McKeever, J., and Frankenberg, C.: Satellite observations of atmospheric methane and their value for quantifying methane emissions, Atmos. Chem. Phys., 16, 14371-14396, https://doi.org/10.5194/acp-16-143712016, 2016.

Jervis, D., McKeever, J., Durak, B. O. A., Sloan, J. J., Gains, D., Varon, D. J., Ramier, A., Strupler, M., and Tarrant, E.: The GHGSat-D imaging spectrometer, Atmos. Meas. Tech. Discuss., https://doi.org/10.5194/amt-2020-301, in review, 2020.

Kalnay, E., Kanamitsu, M., Kistler, R., Collins, W., Deaven, D., Gandin, L., Iredell, M., Saha, S., White, G., Woollen, J., Zhu, Y., Chelliah, M., Ebisuzaki, W., Higgins, W., Janowiak, J., Mo, K. C., Ropelewski, C., Wang, J., Leetmaa, A., Reynolds, R., Jenne, R., and Joseph, D.: The NCEP/NCAR 40-year reanalysis project, B. Am. Meteorol. Soc., 77, 437-471, https://doi.org/10.1175/15200477(1996)077<0437:TNYRP>2.0.CO;2, 1996.

Kiemle, C., Kawa, S. R., Quatrevalet, M., and Browell, E. V.: Performance simulations for a spaceborne methane lidar mission, J. Geophys. Res., 119, 4365-4379, https://doi.org/10.1002/2013JD021253, 2014.

Kirschke, S., Bousquet, P., Ciais, P., Saunois, M., Canadell, Josep G., Dlugokencky. E. J., Bergamaschi, P., Bergmann, D., Blake, D. R., Bruhwiler, L., Cameron-Smith, P., Castaldi, S., Chevallier, F., Feng, L., Fraser, A., Heimann, M, Hodson, E. L., Houweling, S., Josse, B., Fraser, P. J., Krummel, P. B., Lamarque, J.F., Langenfelds, R. L., Le Quere, C., Naik, V., O’Doherty, S., Palmer, P. I., Pison, I., Plummer, D., Poulter, B., Prinn, R. G., Rigby, M., Ringeval, B., Santini, M. Schmidt, M., Shindell, D. T., Simpson, I. J., Spahni, R., Steele, L. P., Strode, S. A., Sudo, K., Szopa, S., van der Werf, G. R., Voulgarakis, A., van Weele, M., Weiss, R. F., Williams, J. E., and Zeng, G.: Three decades of global methane sources and sinks, Nat. Geosci., 6, 813-823, https://doi.org/10.1038/ngeo1955, 2013.

Kort, E. A., Frankenberg, C., Costigan, K. R., Lindenmaier, R., Dubey, M. K., and Wunch, D.: Four corners: the largest US methane anomaly viewed from space, Geophys. Res. Lett., 41, 6898-6903, https://doi.org/10.1002/2014GL061503, 2014.

Kuze, A., Suto, H., Shiomi, K., Kawakami, S., Tanaka, M., Ueda, Y., Deguchi, A., Yoshida, J., Yamamoto, Y., Kataoka, F., Taylor, T. E., and Buijs, H. L.: Update on GOSAT TANSOFTS performance, operations, and data products after more than 6 years in space, Atmos. Meas. Tech., 9, 2445-2461, https://doi.org/10.5194/amt-9-2445-2016, 2016.

Kvenvolden, K. A.: Methane hydrate - A major reservoir of carbon in the shallow geosphere?, Chem. Geol., 71, 41-51, https://doi.org/10.1016/0009-2541(88)90104-0, 1988.

Kvenvolden, K. A. and Rogers, B. W.: Gaia's breath global methane exhalations, Mar. Petrol. Geol., 22, 579-590, https://doi.org/10.1016/j.marpetgeo.2004.08.004, 2005.
Macdonald, J. A., Fowler, D., Hargreaves, K. J., Skiba, U., Leith, I. D., and Murray, M. B.: Methane emission rates from a northern wetland; response to temperature, water table and transport, Atmos. Environ., 32, 3219-3227, https://doi.org/10.1016/S13522310(97)00464-0, 1998.

Manolakis, D., Truslow, E., Pieper, M., Cooley, T., and Brueggeman, M.: Detection algorithms in hyperspectral imaging systems: An overview of practical algorithms, IEEE Signal Proc. Mag., 31, 24-33, https://doi.org/10.1109/MSP.2013.2278915, 2014.

McKeever, J., Durak, B. O. A., Gains, D., Varon, D. J., Germain, S., and Sloan, J. J.: GHGSat-D: Greenhouse gas plume imaging and quantification from space using a Fabry-Perot imaging spectrometer, 2017 Fall Meeting, AGU, New Orleans, LA, 1115 December 2017, Abstract A33G-1360, 2017.

Merchant, C. J., Le Borgne, P., Roquet, H., and Legendre, G.: Extended optimal estimation techniques for sea surface temperature from the Spinning Enhanced Visible and InfraRed Imager (SEVIRI), Remote Sens. Environ., 131, 287-297, https://doi.org/10.1016/j.rse.2012.12.019, 2013.

Myhre, G., Shindell, D., Bréon, F.-M., Collins, W., Fuglestvedt, J., Huang, J., Koch, D., Lamarque, J.-F., Lee, D., Mendoza, B., Nakajima, T., Robock, A., Stephens, G., Takemura, T., and Zhang, H.: Anthropogenic and Natural Radiative Forc-ing, in: Climate Change 2013: The Physical Science Basis. Contribution of Working Group I to the Fifth Assessment Report of the Intergovernmental Panel on Climate Change, edited by: Stocker, T. F., Qin, D., Plattner, G.-K., Tignor, M., Allen, S. K., Boschung, J., Nauels, A., Xia, Y., Bex, V., and Midgley, P. M., Cambridge University Press, Cambridge, United Kingdom and New York, NY, USA, 2013.

Nisbet, E. G., Dlugokencky, E. J., and Bousquet, P.: Methane on the rise-Again, Science, 343, 493-495, https://doi.org/10.1126/science.1247828, 2014.

Nisbet, E. G., Dlugokencky, E. J., Manning, M. R., Lowry, D., Fisher, R. E., France, J. L., Michel, S. E., Miller, J. B., White, J. W. C., Vaughn, B., Bousquet, P., Pyle, J. A., Warwick, N. J., Cain, M., Brownlow, R., Zazzeri, G., Lanoisellé, M., Manning, A. C., Gloor, E., Worthy, D. E. J., Brunke, E.-G., Labuschagne, C., Wolff, E. W., and Ganesan, A. L.: Rising atmospheric methane: 2007-2014 growth and isotopic shift, Global Biogeochem. Cy., 30, 1356-1370, https://doi.org/10.1002/2016GB005406, 2016.

NOAA/GML (NOAA Earth System Research Laboratory Global Monitoring Laboratory): Trends in Atmospheric Methane: Global $\mathrm{CH}_{4}$ Monthly Means, available at: https://esrl.noaa.gov/ gmd/ccgg/trends_ch4/, last access: 27 November 2020.

O’Dell, C. W., Eldering, A., Wennberg, P. O., Crisp, D., Gunson, M. R., Fisher, B., Frankenberg, C., Kiel, M., Lindqvist, H., Mandrake, L., Merrelli, A., Natraj, V., Nelson, R. R., Osterman, G. B., Payne, V. H., Taylor, T. E., Wunch, D., Drouin, B. J., Oyafuso, F., Chang, A., McDuffie, J., Smyth, M., Baker, D. F., Basu, S., Chevallier, F., Crowell, S. M. R., Feng, L., Palmer, P. I., Dubey, M., García, O. E., Griffith, D. W. T., Hase, F., Iraci, L. T., Kivi, R., Morino, I., Notholt, J., Ohyama, H., Petri, C., Roehl, C. M., Sha, M. K., Strong, K., Sussmann, R., Te, Y., Uchino, O., and Velazco, V. A.: Improved retrievals of carbon dioxide from Orbiting Carbon Observatory- 2 with the version 8 ACOS algorithm, Atmos. Meas. Tech., 11, 6539-6576, https://doi.org/10.5194/amt11-6539-2018, 2018. 
Polonsky, I. N., O’Brien, D. M., Kumer, J. B., O’Dell, C. W., and the geoCARB Team: Performance of a geostationary mission, geoCARB, to measure $\mathrm{CO}_{2}, \mathrm{CH}_{4}$ and $\mathrm{CO}$ columnaveraged concentrations, Atmos. Meas. Tech., 7, 959-981, https://doi.org/10.5194/amt-7-959-2014, 2014.

Roberts, D. A., Bradley, E. S., Cheung, R., Leifer, I., Dennison, P. E., and Margolis, J. S.: Mapping methane emissions from a marine geological seep source using imaging spectrometry, Remote Sens. Environ., 114, 592-606, https://doi.org/10.1016/j.rse.2009.10.015, 2010.

Rodgers, C. D.: Inverse Methods for Atmospheric Sounding: Theory and Practice, World Scientific, Singapore, 2000.

Rothman, L. S., Gordon, I. E., Barbe, A., Benner, D. C., Bernath, P. E., Birk, M., Boudon, V., Brown, L. R., Campargue, A., Champion, J. P., Chance, K., Coudert, L. H., Dana, V., Devi, V. M., Fally, S., Flaud, J. M., Gamache, R. R., Goldman, A., Jacquemart, D., Kleiner, I., Lacome, N., Lafferty, W. J., Mandin, J. Y., Massie, S. T., Mikhailenko, S. N., Miller, C. E., Moazzen-Ahmadi, N., Naumenko, O. V., Nikitin, A. V., Orphal, J., Perevalov, V. I., Perrin, A., Predoi-Cross, A., Rinsland, C. P., Rotger, M., Šimečková, M., Smith, M. A. H., Sung, K., Tashkun, S. A., Tennyson, J., Toth, R. A., Vandaele, A. C., and Vander Auwera, J.: The HITRAN 2008 molecular spectroscopic database, J. Quant. Spectrosc. Ra., 110, 533-572, https://doi.org/10.1016/j.jqsrt.2009.02.013, 2009.

Schaefer, H., Fletcher, S. E. M., Veidt, C., Lassey, K. R., Brailsford, G. W., Bromley, T. M., Dlugokencky, E. J., Michel, S. E., Miller, J. M., Levin, I., Lowe, D. C., Martin, R. J., Vaughn, B. H., and White, J. W. C.: A 21st-century shift from fossil-fuel to biogenic methane emissions indicated by ${ }^{13} \mathrm{CH}_{4}$, Science, 352, 80-84, https://doi.org/10.1126/science.aad2705, 2016.

Schaefer, K., Lantuit, H., Romanovsky, V. E., Schuur, E. A. G., and Witt, R.: The impact of the permafrost carbon feedback on global climate, Environ. Res. Lett., 9, 085003, https://doi.org/10.1088/1748-9326/9/8/085003, 2014.

Schuur, E. A. G., McGuire, A. D., Schädel, C., Grosse, G., Harden, J. W., Hayes, D. J., Hugelius, G., Koven, C. D., Kuhry, P., Lawrence, D. M., Natali, S. M., Olefeldt, D., Romanovsky, V. E., Schaefer, K., Turetsky, M. R., Treat, C. C., and Vonk, J. E.: Climate change and the permafrost carbon feedback, Nature, 520, 171-179, https://doi.org/10.1038/nature14338, 2015.

Seinfeld, J. H. and Pandis, S. N.: Atmospheric Chemistry and Physics: From Air Pollution to Climate Change, Wiley, New Jersey, USA, 2006.

Spurr, R. and Natraj, V.: A linearized two-stream radiative transfer code for fast approximation of multiplescatter fields, J. Quant. Spectrosc. Ra., 112, 2630-2637, https://doi.org/10.1016/j.jqsrt.2011.06.014, 2011.

Themelis, N. J. and Ulloa, P. A.: Methane generation in landfills, Renewable Energy, 32, 1243-1257, https://doi.org/10.1016/j.renene.2006.04.020, 2007.

Thompson, D. R., Leifer, I., Bovensmann, H., Eastwood, M., Fladeland, M., Frankenberg, C., Gerilowski, K., Green, R. O., Kratwurst, S., Krings, T., Luna, B., and Thorpe, A. K.: Real-time remote detection and measurement for airborne imaging spectroscopy: a case study with methane, Atmos. Meas. Tech., 8, 4383-4397, https://doi.org/10.5194/amt-8-4383-2015, 2015.

Thorpe, A. K., Roberts, D. A., Bradley, E. S., Funk, C. C., Dennison, P. E., and Leifer, I.: High resolution mapping of methane emissions from marine and terrestrial sources using a Cluster-Tuned Matched Filter technique and imaging spectrometry, Remote Sens. Environ., 134, 305-318, https://doi.org/10.1016/j.rse.2013.03.018, 2013.

Thorpe, A. K., Frankenberg, C., and Roberts, D. A.: Retrieval techniques for airborne imaging of methane concentrations using high spatial and moderate spectral resolution: application to AVIRIS, Atmos. Meas. Tech., 7, 491-506, https://doi.org/10.5194/amt-7-491-201, 2014.

Varon, D. J., McKeever, J., Jervis, D., Maasakkers, J. D., Pandey, S., Houweling, S., Aben, I., Scarpelli, T., and Jacob, D. J.: Satellite discovery of anomalously large methane point sources from oil/gas production, Geophys. Res. Lett., 46, 13507-13516, https://doi.org/10.1029/2019GL083798, 2019.

Veefkind, J. P., Aben, I., McMullan, K., Forster, H., de Vries, J.,Otter, G., Claas, J., Eskes, H. J., de Haan, J. F., Kleipool, Q., van Weele, M., Hasekamp, O., Hoogeveen, R., Landgraf, J., Snel, R., Tol, P., Ingmann, P., Voors, R., Kruizinga, B., Vink, R., Visser, H., and Levelt, P. F.: TROPOMI on the ESA Sentinel-5 Precursor: A GMES mission for global observations of the atmospheric composition for climate, air quality and ozone layer applications, Remote Sens. Environ., 120, 70-83, https://doi.org/10.1016/j.rse.2011.09.027, 2012.

Walter, K. M., Zimov, S. A., Chanton, J. P., Verbyla, D., and Chapin III, F. S.: Methane bubbling from Siberian thaw lakes as a positive feedback to climate warming, Nature, 443, 71-75, https://doi.org/10.1038/nature05040, 2006.

WCRP (World Climate Research Program): A preliminary cloudless standard atmosphere for radiation computation, International Association for Meteorology and Atmospheric Physics, Radiation Commission, Boulder, CO, USA, WMO/TD-No. 24; WCPNo. 112, March 1986.

Wofsy, S. C. and Hamburg, S: MethaneSAT - A new observing platform for high resolution measurements of methane and carbon dioxide, 2019 Fall Meeting, AGU, San Francisco, CA, 9-13 December 2019, Abstract A53F-02, 2019.

Woodwell, G. M., Mackenzie, F. T., Houghton, R. A., Apps, M., Gorham, E., and Davidson, E.: Biotic feedbacks in the warming of the earth, Climatic Change, 40, 495-518, https://doi.org/10.1023/A:1005345429236, 1998.

Worden, J., Kulawik, S., Frankenberg, C., Payne, V., Bowman, K., Cady-Peirara, K., Wecht, K., Lee, J.-E., and Noone, D.: Profiles of $\mathrm{CH}_{4}, \mathrm{HDO}, \mathrm{H}_{2} \mathrm{O}$, and $\mathrm{N} 2 \mathrm{O}$ with improved lower tropospheric vertical resolution from Aura TES radiances, Atmos. Meas. Tech., 5, 397-411, https://doi.org/10.5194/amt-5397-2012, 2012.

Xi, X., Natraj, V., Shia, R. L., Luo, M., Zhang, Q., Newman, S., Sander, S. P., and Yung, Y. L.: Simulated retrievals for the remote sensing of $\mathrm{CO}_{2}, \mathrm{CH}_{4}, \mathrm{CO}$, and $\mathrm{H}_{2} \mathrm{O}$ from geostationary orbit, Atmos. Meas. Tech., 8, 4817-4830, https://doi.org/10.5194/amt8-4817-2015, 2015.

Xiong, X., Barnet, C., Maddy, E., Sweeney, C., Liu, X., Zhou, L., and Goldberg, M.: Characterization and validation of methane products from the Atmospheric Infrared Sounder (AIRS), J. Geophys. Res., 113, G00A01, https://doi.org/10.1029/2007JG000500, 2008.

Xiong, X., Barnet, C., Maddy, E. S., Gambacorta, A., King, T. S., and Wofsy, S. C.: Mid-upper tropospheric methane retrieval 
from IASI and its validation, Atmos. Meas. Tech., 6, 2255-2265, https://doi.org/10.5194/amt-6-2255-2013, 2013.

Yoshida, Y., Kikuchi, N., Morino, I., Uchino, O., Oshchepkov, S., Bril, A., Saeki, T., Schutgens, N., Toon, G. C., Wunch, D., Roehl, C. M., Wennberg, P. O., Griffith, D. W. T., Deutscher, N. M., Warneke, T., Notholt, J., Robinson, J., Sherlock, V., Connor, B., Rettinger, M., Sussmann, R., Ahonen, P., Heikkinen, P., Kyrö, E., Mendonca, J., Strong, K., Hase, F., Dohe, S., and Yokota, T.: Improvement of the retrieval algorithm for GOSAT SWIR $\mathrm{XCO}_{2}$ and $\mathrm{XCH}_{4}$ and their validation using TCCON data, Atmos. Meas. Tech., 6, 1533-1547, https://doi.org/10.5194/amt-61533-2013, 2013.

Zeng, Z.-C., Zhang, Q., Natraj, V., Margolis, J. S., Shia, R.-L., Newman, S., Fu, D., Pongetti, T. J., Wong, K. W., Sander, S. P., Wennberg, P. O., and Yung, Y. L.: Aerosol scattering effects on water vapor retrievals over the Los Angeles Basin, Atmos. Chem. Phys., 17, 2495-2508, https://doi.org/10.5194/acp17-2495-2017, 2017.
Zeng, Z.-C., Natraj, V., Xu, F., Pongetti, T. J., Shia, R.-L., Kort, E. A., Toon, G. C., Sander, S. P., and Yung, Y. L.: Constraining aerosol vertical profile in the boundary layer using hyperspectral measurements of oxygen absorption, Geophys. Res. Lett., 45, 10772-10780, https://doi.org/10.1029/2018GL079286, 2018.

Zhang, Q., Natraj, V., Li, K.-F., Shia, R.-L., Fu, D., Pongetti, T. J., Sander S. P., Roehl, C. M., and Yung, Y. L.: Accounting for aerosol scattering in the CLARS retrieval of column averaged $\mathrm{CO}_{2}$ mixing ratios, J. Geophys. Res.-Atmos., 120, 7205-7218, https://doi.org/10.1002/2015JD023499, 2015.

Zhang, Q., Shia, R. -L., Sander, S. P., and Yung, Y. L.: $\mathrm{X}_{\mathrm{CO} 2}$ retrieval error over deserts near critical surface albedo, Earth Space Sci., 2, 1-10, https://doi.org/10.1002/2015EA000143, 2016. 